\title{
Contactless temperature measurement in wire-based electron beam additive manufacturing Ti-6Al-4V
}

\author{
F. Pixner ${ }^{1}\left(\mathbb{D} \cdot\right.$ R. Buzolin $^{1} \cdot$ S. Schönfelder ${ }^{2} \cdot$ D. Theuermann ${ }^{1} \cdot$ F. Warchomicka ${ }^{1} \cdot$ N. Enzinger ${ }^{1}$
}

Received: 25 November 2020 / Accepted: 16 February 2021 / Published online: 4 March 2021

(C) The Author(s) 2021

\begin{abstract}
The complex thermal cycles and temperature distributions observed in additive manufacturing (AM) are of particular interest as these define the microstructure and the associated properties of the part being built. Due to the intrinsic, layer-by-layer material stacking performed, contact methods to measure temperature are not suitable, and contactless methods need to be considered. Contactless infrared irradiation techniques were applied by carrying out thermal imaging and point measurement methods using pyrometers to determine the spatial and temporal temperature distribution in wire-based electron beam AM. Due to the vacuum, additional challenges such as element evaporation must be overcome and additional shielding measures were taken to avoid interference with the contactless techniques. The emissivities were calibrated by thermocouple readings and geometric boundary conditions. Thermal cycles and temperature profiles were recorded during deposition; the temperature gradients are described and the associated temperature transients are derived. In the temperature range of the $\alpha+\beta$ field, the cooling rates fall within the range of 180 to $350^{\circ} \mathrm{C} / \mathrm{s}$, and the microstructural characterisation indicates an associated expected transformation of $\beta \rightarrow \alpha^{\prime}+\alpha$ with corresponding cooling rates. Fine acicular $\alpha$ and $\alpha^{\prime}$ formed and local misorientation was observed within $\alpha$ as a result of the temperature gradient and the formation of the $\alpha$.
\end{abstract}

Keywords Ti-6Al-4V · Additive manufacturing $\cdot$ Contactless temperature measurement $\cdot$ Wire-based

\section{Introduction}

Additive manufacturing (AM) is an emerging technology that offers a variety of new and interesting possibilities. Using this technology, companies can produce finished and semifinished products that have optimised geometry, technological and metallurgical properties but also economic benefits. AM covers a wide range of processes, which can generally be classified according to the ISO 17296-2:2015 standard [1] as follows: vat photopolymerisation, material jetting, binder jetting, powder bed fusion (PBF), material extrusion, directed energy deposition (DED) and sheet lamination. The PBF

Recommended for publication by Commission I - Additive Manufacturing, Surfacing, and Thermal Cutting

F. Pixner

florian.pixner@tugraz.at

1 Institute of Materials Science, Joining and Forming, Graz University of Technology, Graz, Austria

2 pro-beam additive $\mathrm{GmbH}$, Gilching, Germany method is widely used to process metallic materials, but economical DED processes (e.g. LDM, WAAM) are also suitable for the production of AM components. Numerous metallic materials can be used, such as steels [2-4], aluminium materials [5-7] and nickel-based alloys [8-10]. Titanium and its alloys are of particular interest, especially to the aerospace industry, due to their excellent properties, including their high strength to density ratio and their resistance to corrosive environments [11]. However, the route followed to produce such alloys is highly complex, cost-intensive and has considerable drawbacks. To overcome these disadvantages, a high material utilisation ratio should be achieved (buy-to-fly ratio); this can be achieved by using DED AM processes [12]. When reactive materials are used in production, such as Ti-based alloys, few suitable DED processes are available, and a remarkable number of requirements must be met to create an appropriate shielding environment to avoid contamination. To prevent the oxidation of the AM parts produced using the WAAM process, it is necessary to provide a high argon gas flow rate. This, in turn, leads to significant forced convection cooling, and careful attention needs to be paid to thermal management and interpass conditions [13-15]. Oxidation and dissolved 
oxygen in the titanium matrix causes an undesirably rapid reduction in the fracture elongation and increases its strength due to solid-solution hardening $[16,17]$. Electron beam processes serve as a useful alternative; because the process is carried out under vacuum, they are suitable for processing titanium and contamination by oxygen is avoided [18]. Electron beam freeform fabrication $\left(\mathrm{EBF}^{3}\right)$ is one such wirebased DED process that uses an electron beam as a heat source. The feasibility of applying this process to titanium alloys has been already reported in the literature [19-24].

All AM processes display complex multiple thermal cycles and transient temperature profiles. The temperature distribution influences many factors, such as the melt pool geometry [25-27]. The thermal history of the components defines various metallurgical phenomena, microstructural features, and properties related to these components $[11,28]$. In addition, by taking temperature measurements and gaining knowledge about temperature profiles, on-line process control / monitoring can be facilitated and applied for thermal non-destructive evaluation (NDE) purposes to stabilize and further improve the process [29-31]. Consequently, researchers have shown particular interest in increasing the knowledge about the thermal cycles and temperature distribution in AM by conducting experimental measurements and numerical thermal simulations. Due to the nature of the process, which involves intrinsic layer-by-layer material stacking and continuous build-up, contact methods to measure temperature are not as suitable as contactless methods. The use of the latter, such as thermal imaging or point measurement methods, is required to collect spatial and temporal temperature information for the region of interest [32].

Li et al. [31] summarised the recent trends and provided an overview of possible contactless in-situ temperature measurement techniques that could be applied in metallic AM. These contactless techniques include conventional infrared irradiation temperature measurement methods (single-wavelength / one-colour technique) and two- or more wavelength (multicolour-) techniques [31]. When multi-colour pyrometers are applied, it is generally assumed that the ratio between the emissivities for the respective spectral ranges is known and that the emissivity ratios are constant, rather than temperaturedependent. Each material has its own emissivity-towavelength relationship, and costly multi-colour pyrometers with a specific wavelength range can often not be used to measure temperature with sufficient accuracy due to the changing emissivity ratio of the material [31-33]. Onecolour infrared irradiation techniques offer cost-effective alternatives; these require the user to have knowledge about and quantitative values for the emissivity of a material as well as its present condition [32]. The material emissivity needs to be carefully calibrated and selected before such measurements are taken, as the emissivity varies according to the wavelength, temperature and surface conditions. The latter include the roughness, contamination level, oxidation level or surface stress state of the material $[34,35]$. Due to its simplicity, robustness and cost efficiency, this contactless technology has already been tested in WAAM processes to investigate the effect of heat accumulation on the interlayer temperatures [33, 36, 37], alterations in arc characteristics [38] and changes in metallurgical and mechanical properties $[36,37,39]$ during the layer-by-layer stacking process. However, several points need to be considered when WAAM processes are carried out, such as the effects of transient surface contamination (e.g. oxidation, slag and smoke), changing transmissivity/optical path (welding fume), and interference from the arc light, since the arc produces radiation that covers the entire spectrum. In an electron beam freeform fabrication process, on the other hand, the presence of vacuum prevents surface contamination (which can otherwise be comparatively severe), provides a more constant transmittance/optical path and prevents interference from a heat source. On the other hand, new challenges also arise when performing contactless temperature measurements during metal processing under vacuum. Limitations in accessibility and devices that are suitable for use under vacuum conditions need to be taken into account. Vacuum feedthroughs for electrical signals are limited and the resulting $\mathrm{X}$-rays during beam exposure may damage the electronics implemented in the chamber without additional shielding measures. During processing and metal deposition, elements with a high saturated vapour pressure tend to evaporate under vacuum conditions and can interfere with contactless measurements. The evaporative loss of aluminium that occurs when Ti- $6 \mathrm{Al}-4 \mathrm{~V}$ is processed under vacuum has already been reported in the literature [21, 23, 40-42]. Additional measures have to be taken to ensure that the temperature can be recorded continuously and without disturbance inside the vacuum chamber. Contactless measurements on workpieces inside the chamber, e.g. by IR pyrometers, can in principle also be carried out from outside the chamber [43]. Electron beam vacuum chambers are designed with a viewing port to provide a direct view into the chamber through a small (lead) glass window. However, measurements from outside the chamber are subject to uncertainties because the lead glass used in the viewing port provides sufficient optical protection from UV and IR radiation, changes in transmissivity, and an increase in the measurement distance between the pyrometer and the region of interest, resulting in low spatial resolution.

The recent literature [30] contains little information about contactless temperature measurements in vacuum-based $\mathrm{EBF}^{3}$. The present study was carried out to demonstrate the feasibility of contactless temperature measurement methods when they are implemented inside a vacuum chamber (pyrometer measurement method) and under normal atmospheric conditions (thermal imaging technique). Appropriate methods for positioning and protecting the devices from the metal vapour during processing are presented. Thermal cycles and 
temperature profiles, described by presenting isotherms, are determined during electron beam AM, and the cooling rates are associated with the observed microstructure of the deposited weld metal.

\section{Experimental}

\subsection{Materials}

A solid wire of titanium alloy Ti-6Al-4V AWS A5.16 ER Ti5 (EN ISO 24034) with a diameter of $\varnothing 1.2 \mathrm{~mm}$ was used in this study. All experiments and the weld bead deposition were performed on a titanium grade 5 substrate with dimensions of $200 \times 50 \times 13 \mathrm{~mm}$. The chemical composition of the applied materials is listed in Table 1. The proportion of the elements aluminium $(\mathrm{Al})$, vanadium $(\mathrm{V})$ and iron $(\mathrm{Fe})$ were determined by atomic absorption spectroscopy. The interstitial element carbon (C) was identified by applying the solid-state infrared absorption detection method with LECO CS230 (LECO Corporation, St. Joseph, MO, USA) and nitrogen (N) was identified by applying the thermal conductivity detection method with LECO ON 736 (LECO Corporation, St. Joseph, MO, USA).

\subsection{Equipment}

\subsubsection{Electron beam welding device}

The experiments were performed using the electron beam welding device pro-beam EBG 45-150 k14 (pro-beam GmbH \& Co. KGaA, Gilching, Germany). A maximum acceleration voltage and beam current of up to $150 \mathrm{kV}$ and $300 \mathrm{~mA}$ can be supplied by this device. The working chamber provides a volume of approx. $1.4 \mathrm{~m}^{3}$ with a vacuum level below $5 \times 10^{-3}$ mbar. Inside the chamber, workpiece handling was performed by manipulating a three-axis work table, while the electron beam gun and welding position $\mathrm{PA} / 1 \mathrm{~F}$ were fixed. The solid wire was fed by pressure rollers and ended in a water-cooled wire nozzle which could be moved along all three axes. The angle between the substrate and the fed wire was $35^{\circ}$ [44], and the distance between the wire nozzle and the substrate surface was set at $8 \mathrm{~mm}$. A height distance of $1 \mathrm{~mm}$ between the wire tip and the substrate surface was set to enable a stable liquid metal bridge material transfer to take place during the process.

\subsubsection{One-colour pyrometer}

To perform pyrometry, a one-colour pyrometer Sensortherm METIS M318 (Sensortherm GmbH, Sulzbach, Germany) was used with a temperature range and spectral range of 150 to $1200{ }^{\circ} \mathrm{C}$ and $1.65-2.1 \mu \mathrm{m}$. The emissivity and transmissivity can be selected independently and values can be set variably with this device. The pyrometer was mounted on the wire feed unit in the vacuum chamber and aligned at $35^{\circ}$ at a radial distance of approx. $450 \mathrm{~mm}$ from the substrate. The focal point was adjusted on the material surface, and a spot size of $\varnothing 2 \mathrm{~mm}$ was used in all experiments.

When Ti-6Al-4V is processed under a vacuum, mainly aluminium evaporates from the melt pool. These evaporation losses coat the pyrometer lens, resulting in continuous changes in the transmittance and interference with the contactless measurement. To keep this evaporation from influencing the measurement, the setup was extended and a protective device was designed and attached to the pyrometer. The device operated as follows: a heat-resistant polyimide film (up to 400 ${ }^{\circ} \mathrm{C}$ ) is moved continuously in front of the pyrometer lens (Fig. 1a) by a vacuum-compatible electric motor. In this way, the thickness of the aluminium coating is kept constant and depends mainly on the speed with which the film is moved. If the conveying speed is fast enough, the aluminium condensation on the polyimide film is no longer visible macroscopically, and it is possible to continuously record the temperature (Fig. 1b).

\subsubsection{Near-infrared camera}

Temperature fields were recorded with a near-infrared (NIR) camera Optris PI 1M (Optris GmbH, Berlin, Germany) that covered the spectral range of $0.85-1.1 \mu \mathrm{m}$ and a temperature range of $675-1800{ }^{\circ} \mathrm{C}$. The NIR camera produces images with a resolution of $764 \times 480$ pixels and has a maximum frame rate of $32 \mathrm{~Hz}$. The emissivity and transmissivity can be selected independently and values can be set variably with this device. The camera was positioned outside the vacuum chamber in the optical viewing system in addition to the integrated CCD camera. A dichroic mirror acts as a wavelength-specific beam splitter and enables the use of the CCD camera to
Table 1 Measured chemical composition of applied filler wire AWS A5.16 ER Ti5 and Ti-6Al4V substrate; n.m., not measured

\begin{tabular}{llllllll}
\hline & $\begin{array}{l}\mathrm{Al} \\
(\text { wt. \%) }\end{array}$ & $\begin{array}{l}\mathrm{V} \\
(\text { wt. \%) }\end{array}$ & $\begin{array}{l}\mathrm{Fe} \\
(\text { wt. \%) }\end{array}$ & $\begin{array}{l}\mathrm{Ti} \\
\text { (wt. \%) }\end{array}$ & $\begin{array}{l}\mathrm{C} \\
\text { (wt. \%) }\end{array}$ & $\begin{array}{l}\mathrm{N} \\
\text { (wt. \%) }\end{array}$ & $\begin{array}{l}\text { O } \\
\text { (wt. \%) }\end{array}$ \\
\hline Filler wire & 6.36 & 3.48 & 0.11 & bal. & 0.018 & $<0.005$ & n.m. \\
Substrate & 6.38 & 3.49 & 0.21 & bal. & 0.015 & $<0.005$ & n.m. \\
\hline
\end{tabular}




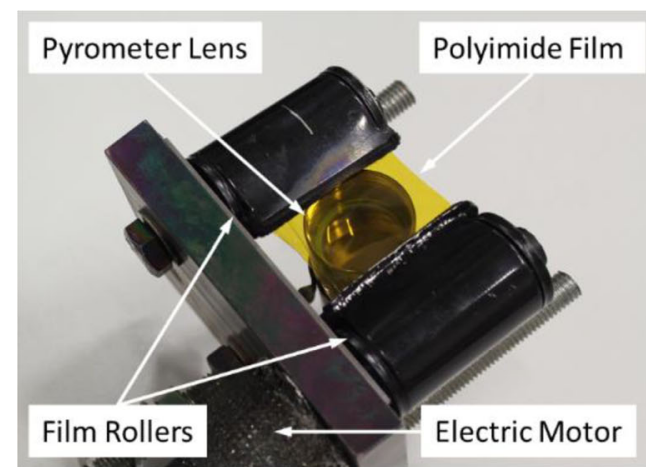

(a)

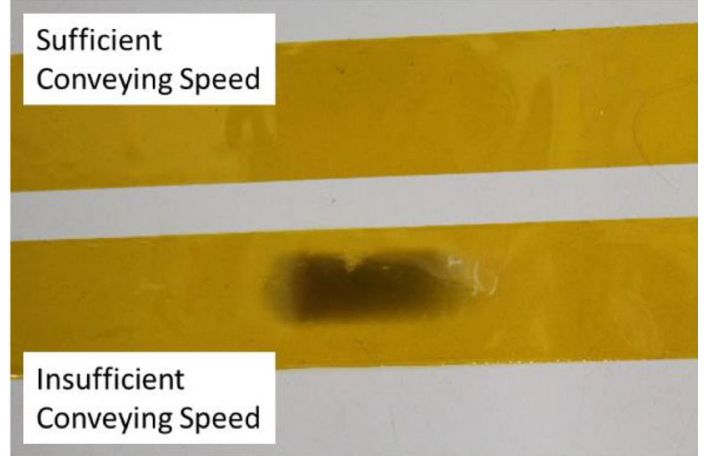

(b)

Fig. 1 a Film protection device and one-colour pyrometer. b Heat-resistant polyimide film with and without feeding after metal deposition due to Ti6Al-4V melting under vacuum

monitor the melt pool at the same time that the NIR camera is used to record the corresponding temperature field. The permanently installed foil transport system in front of the optical viewing prevents a coating of the CCD camera and also of the NIR camera. The schematic illustration of the experimental setup is depicted in Fig. 2.

\subsection{Experimental setup}

\subsubsection{Determination of the emissivity}

The one-colour pyrometer covers a wide temperature range from above the $\beta$-transus temperature to low interlayer temperatures, and a suitable emissivity needs to be determined. The emissivity $\varepsilon_{P}$ was calibrated for the pyrometer system using a benchmark test in which the thermal cycles recorded with the pyrometer and the thermocouples were simultaneously opposed in the temperature range of approx. $200-1000{ }^{\circ} \mathrm{C}$. In the benchmark test, the Ti-6Al-4V sheet was continuously heated by exposing it to an electron beam for $240 \mathrm{~s}$ with an adapted beam figure of concentric circles (maximum diameter of $8 \mathrm{~mm}$; the other diameters as follows: 1.8, 3.8, 5.4, 6.6, 7.4 and $7.8 \mathrm{~mm}$ ) (Fig. 3a). Electron beam processing is characterised by the steep temperature gradient observed from the beam spot to the surrounding area. As such a steep

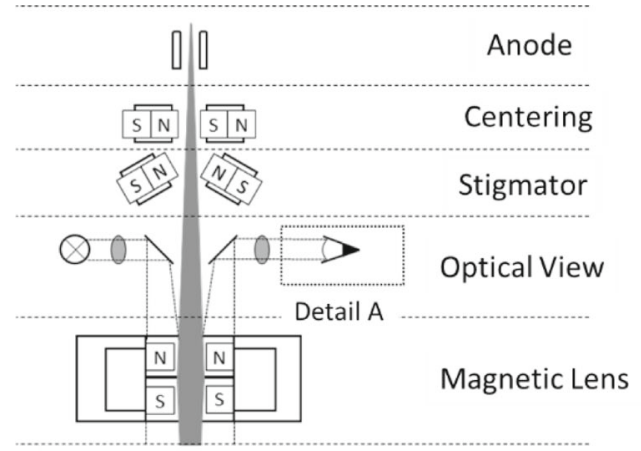

(a) temperature gradient is not desirable during the calibration, the electron beam was slightly defocused to reduce the temperature gradient. The applied process parameters are listed in Table 2 .

Three thermocouples (K1, K2, K3) of type K with diameters of $\varnothing 0.2 \mathrm{~mm}$ were spot-welded along the diameter of a circle that was $\varnothing 9 \mathrm{~mm}$ in the circumferential direction. The reduced diameter of the thermocouples combined with spot welding the thermocouples to the workpiece results in a reduction in response lag [45]. The recorded temperature cycles were then compared with those recorded with a contactless single-colour pyrometer, applying different emission values when the measurement spot was placed at the same radial distance from the centre. A suitable emission coefficient was selected on the basis of a minimum relative temperature difference for the temperature range of interest in the heating and cooling stages.

\subsubsection{Contactless temperature measurements in electron beam additive manufacturing}

Single-track weld beads of Ti-6Al-4V, each with a length of $50 \mathrm{~mm}$, were deposited on the substrate. The relevant main process parameters and beam oscillation parameters are listed in Table 3. As beam figure, ten concentric circles with

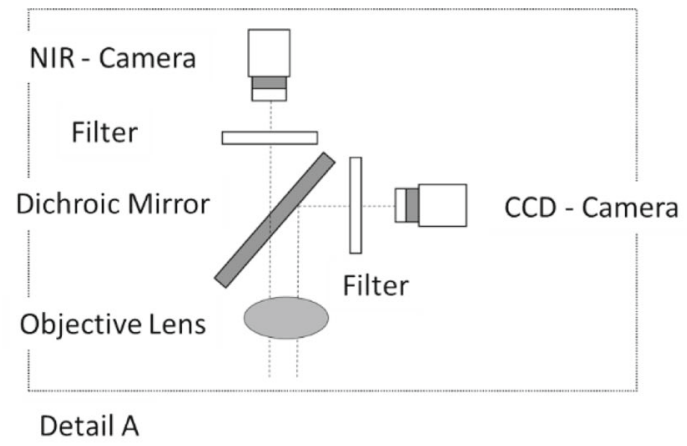

(b)

Fig. 2 a Schematic illustration of the experimental setup. b Detail of the arrangement of the monitoring system, including CCD camera and NIR camera 
Table 2 Summary of input and beam oscillation (bop) parameters established to determine the emissivity for Ti-6Al-4V

\begin{tabular}{|c|c|c|c|}
\hline & & Unit & Values \\
\hline Acceleration voltage & $U_{a c c}$ & $\mathrm{kV}$ & 90 \\
\hline Beam current & $I_{\text {beam }}$ & $\mathrm{mA}$ & 8 \\
\hline Heating time & $t$ & $\mathrm{sec}$ & 240 \\
\hline Focal point & $f_{p}$ & - & $\begin{array}{l}\text { Substrate surface and } \\
\text { defocused by }+100 \mathrm{~mA} 1 \\
\text { ens current }\end{array}$ \\
\hline Working distance & - & $\mathrm{mm}$ & 800 \\
\hline Beam figure (bop) & - & - & Concentric circles \\
\hline Frequency (bop) & $f$ & $\mathrm{~Hz}$ & 1000 \\
\hline Amplitude of deflection (bop) & $x, y$ & $\mathrm{~mm}$ & $\varnothing 8$ \\
\hline
\end{tabular}

diameters from 4.0 to $0.4 \mathrm{~mm}$ in steps of $0.4 \mathrm{~mm}$ were used. The suitability of the parameters has already been demonstrated in [23], and the selected parameter configuration ensures a proper material transfer by the preferred liquid metal bridge transfer mode. Continuous material transfer from the filler wire to the molten pool via the liquid metal bridge results in a smooth and uniform weld surface. The material deposition with the selected parameter configuration results in a track width of about $5.6 \mathrm{~mm}$ and an average height of about $1.7 \mathrm{~mm}$ [23].

The temperature during EBAM at a nominal constant distance of 10 to $35 \mathrm{~mm}$ ( $5 \mathrm{~mm}$ steps from the beam centre on the weld seam centreline) was recorded with a pyrometer using a previously calibrated emissivity $\varepsilon_{P}$ (Fig. 4). The recorded temperature curves were evaluated to identify the peak temperatures in the quasi-stationary stage as a function of their relative offset from the beam centre. This evaluation allowed the derivation of the temperature field, the associated gradients and the cooling rates. The experimental setup is schematically depicted in Fig. 4.
In addition, the temperature field was recorded using the thermal imaging technique and a near-infrared camera. The images were acquired at a frame rate of $8 \mathrm{~Hz}$ for the singletrack deposition of Ti- $6 \mathrm{Al}-4 \mathrm{~V}$, and the region of interest (ROI) was exported at a resolution of $140 \times 60$ pixels. The data were analysed by using MATLAB R2017a software (MathWorks, MA, USA).

\subsection{Metallographic characterisation}

In order to correlate the derived cooling rates with the microstructure of the material, the corresponding cross section was examined. The deposited Ti-6Al-4V was cut perpendicular to the welding direction, and the resulting cross section was hot mounted, ground using $\mathrm{SiC}$ paper, and polished using a silica oxide polishing suspension (OPS) solution prior to the microstructural analysis. The scanning electron microscopy (SEM) investigation was performed using a TESCAN Mira3 microscope (TESCAN, Brno, Czech Republic) equipped with a Hikari detector and a TSL-OIM Data Collector software package for electron backscatter diffraction (EBSD) analysis. EBSD measurements were performed on an area of $50 \mu \mathrm{m} \times 50 \mu \mathrm{m}$, with a step size of $0.1 \mu \mathrm{m}$. An acceleration voltage of $15 \mathrm{kV}$, working distance of $15 \mathrm{~mm}$ and spot size of $8 \mathrm{~nm}$ were used during the EBSD measurements. The generally accepted transition angle between LAGB and HAGB is $15^{\circ}$ in the case of an ideal arrangement of dislocations [46]; this was used to define a high-angle grain boundary. Using the OIM Analysis v. 8 software, a minimum grain size of $0.5 \mu \mathrm{m}$ was chosen to guarantee that each grain consisted of at least five measured pixels. The confidence index was standardised. The EBSD data was then cleaned, considering a minimum confidence index of 0.1 correlated to the neighbour grains.

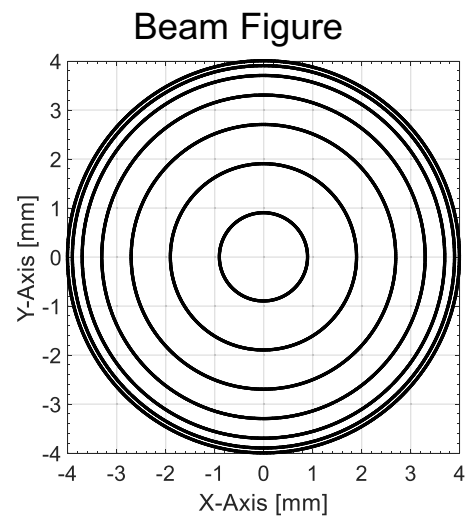

(a)

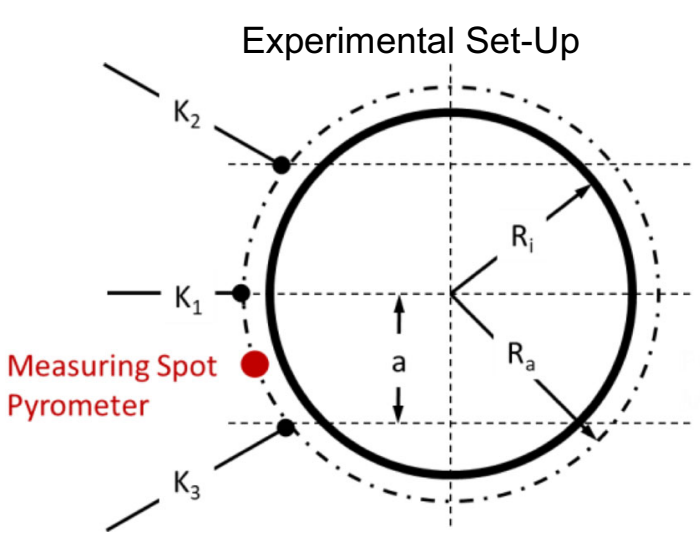

(b)

Fig. 3 Schematic illustration: a concentric circles beam figure and $\mathbf{b}$ experimental setup used to calibrate emission coefficient by comparing thermal cycles recorded by thermocouples and one-colour pyrometer 
Table 3 Summary of input and beam oscillation parameters (bop) for single-track Ti-6Al-4V deposition

\begin{tabular}{llll}
\hline & & Unit & Values \\
\hline Acceleration voltage & $U_{\text {acc }}$ & $\mathrm{kV}$ & 90 \\
Beam current & $I_{\text {beam }}$ & $\mathrm{mA}$ & 17.5 \\
Welding speed & $v_{\text {weld }}$ & $\mathrm{mm} / \mathrm{s}$ & 9.0 \\
Wire feed rate & $V_{\text {wire }}$ & $\mathrm{m} / \mathrm{min}$ & 3.3 \\
Feed angle & $\alpha_{\text {feed }}$ & $\circ$ & 55 \\
Focal point & $f_{p}$ & - & Substrate surface \\
Beam figure (bop) & - & - & Concentric circles \\
Frequency (bop) & $f$ & $\mathrm{~Hz}$ & 1000 \\
Amplitude of deflection (bop) & $x, y$ & $\mathrm{~mm}$ & $\varnothing 4$ \\
\hline
\end{tabular}

\section{Results and discussion}

\subsection{Determination of the emissivity}

According to the literature $[35,47,48]$ and preliminary investigations, an emissivity in the range of $0.280-0.325$ proved to be most promising for calibrating the emissivity for the system and the material surface condition. Depending on the set emissivity, the temperature curves recorded using the pyrometer without contact (solid line) differed from those recorded with contact with thermocouples (dashed line) (Fig. 5).

It was observed that the consistency of the temperature cycles depended not only on the emissivity, but also whether this emissivity was measured during the heating or cooling stage. In the initial phase of heating $(0-5 \mathrm{~s})$, a maximum deviation in the contact and contactless curve could be observed for all tests carried out, regardless of the emissivity chosen. The respective deviations can be attributed to the different response times, spatial resolution offered by the applied methods, which result from the different spot sizes (pyrometer $\varnothing 2 \mathrm{~mm}$, spot-welded thermocouples $\varnothing 0.2 \mathrm{~mm}$ ), as well as differences in the existing transient temperature field and the resulting steep temperature gradients. Since the measured spot sizes and, thus, the range over which the temperature is averaged differed, the average temperature levels as measured by the pyrometer and thermocouples also differed significantly (Fig. 6).

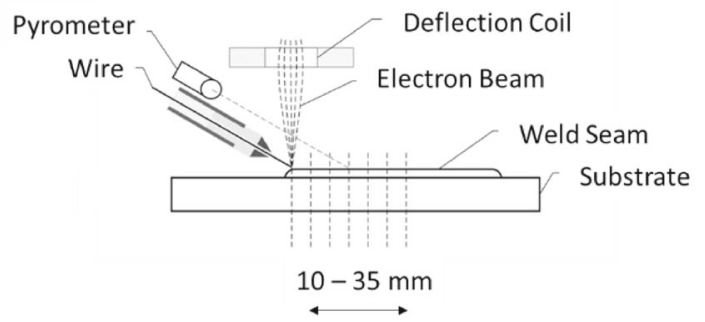

(a)
As the heating continued, and the temperature rose, the transient temperature gradient flattened, leading to an improved approximation of the curves measured. The offset between the temperature levels could be adjusted by adjusting the emissivity, and the selected emissivity $\varepsilon_{P}$ of 0.300 and 0.325 resulted in an acceptable alignment of the curves for the temperature range of interest. Ending the heating stage after $240 \mathrm{~s}$ by switching off the beam initiated the cooling stage. Since the sample is exposed to vacuum, the heat slowly dissipates due to thermal radiation and heat conduction without the contribution of convection.

The deviation between the contactless and contact measurement values observed during the benchmark test can be described by the relative and absolute difference related to the temperature (Fig. 7). In the initial stage of the process at a lower temperature $\left(200-400{ }^{\circ} \mathrm{C}\right)$, i.e. a rapidly evolving transient temperature field, contactless measurement is characterised by a high degree of relative difference and a temperature deviation of 45$15 \%$ and $180-70{ }^{\circ} \mathrm{C}$, respectively. As the exposure time to elevated temperature increases, the temperature transient softens, indicative of an almost steady state. This implies that an equilibrium has occurred between the energy input introduced by the beam and the heat that dissipates by radiation and heat conduction. In each respective stage, the relative and absolute difference can be minimised by setting an appropriate emissivity level. At a given emissivity $\varepsilon_{P}$ of 0.325 , the relative and absolute difference at the end of the heating stage (minimum temperature gradient) and the subsequent cooling stage (moderate temperature gradient) can be reduced to almost zero. Therefore, an emissivity $\varepsilon_{\mathrm{P}}$ of 0.325 was selected for the one-level pyrometer for further experiments.

\subsection{Contactless temperature measurements in electron beam additive manufacturing}

\subsubsection{Thermal cycles by pyrometry}

Thermal cycles recorded by pyrometry with an emissivity $\varepsilon_{\mathrm{P}}$ of 0.325 at a distance of 10 to $35 \mathrm{~mm}$ from the beam centre are shown in Fig. 8. Before the actual metal deposition occurs and the process starts $(<0 \mathrm{~s})$, the initial temperature of $150{ }^{\circ} \mathrm{C}$

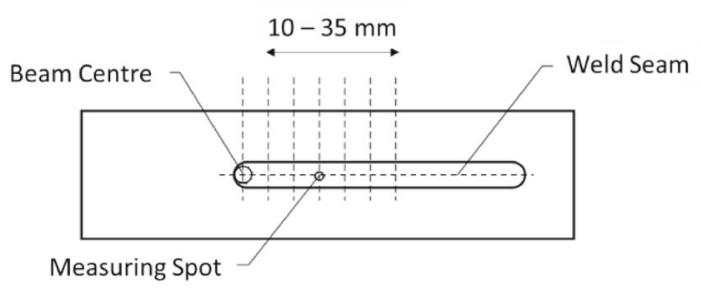

(b)

Fig. 4 Schematic illustration of the experimental setup for contactless measurement with the pyrometer and the related measuring spots: a side view and b top view 
Fig. 5 Contact and contactless recorded temperature curves as recorded with $\mathrm{K}$ thermocouples and a one-colour pyrometer in the designed benchmark test for emissivities $\varepsilon_{\mathrm{P}}$ of a 0.280 , b 0.300 and $\mathbf{c} 0.325$

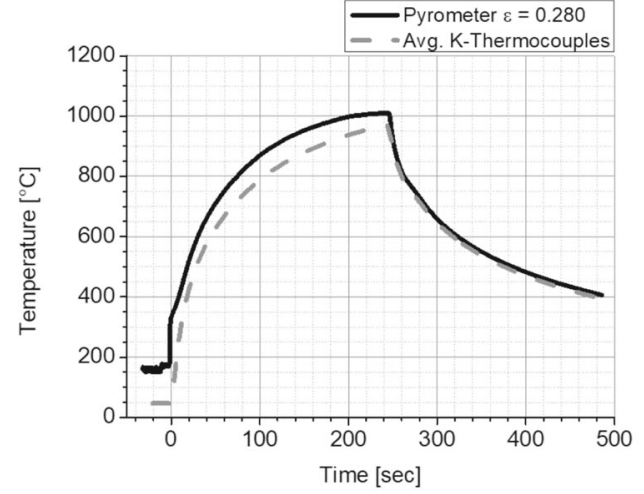

(a)

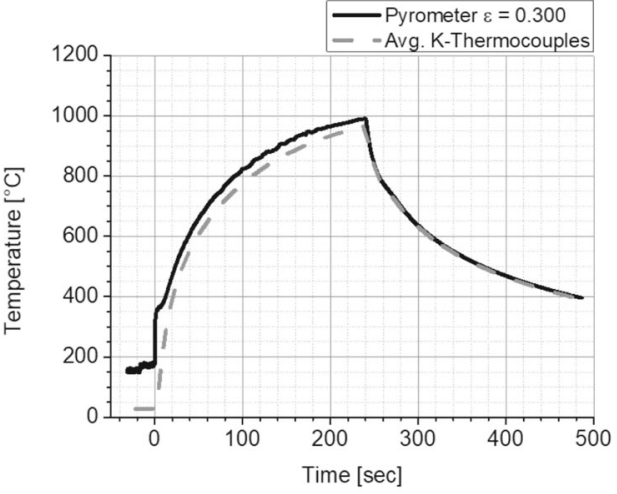

(b)

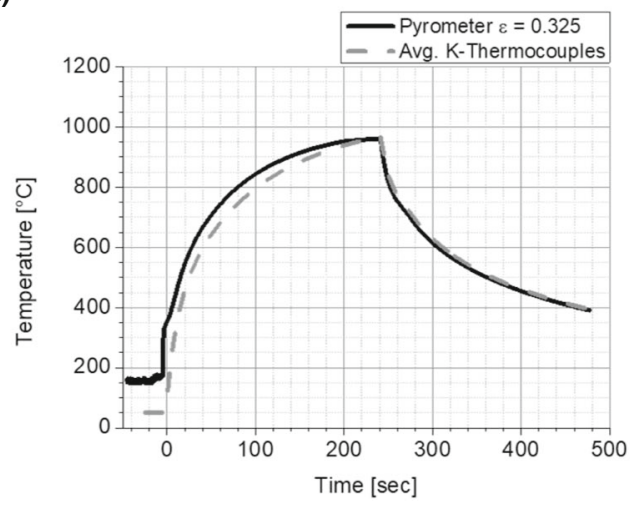

(c)

represents the lower threshold temperature of the pyrometer. This means that only temperatures that exceed this limit can be measured. After the process is initiated and the electron beam is switched on, the temperature increases. The first maximum can be considered as the substrate temperature, since the position of the pyrometer measuring spot is still located on the substrate. Due to the movement of the machine table/substrate during the process, the measuring spot shifts from the substrate to the recently deposited weld bead and records the surface temperature of the deposited metal. Therefore, the second temperature increase represents the transition of the measuring spot from the heated substrate to the deposited weld metal. The maximum temperature is reached at the quasi

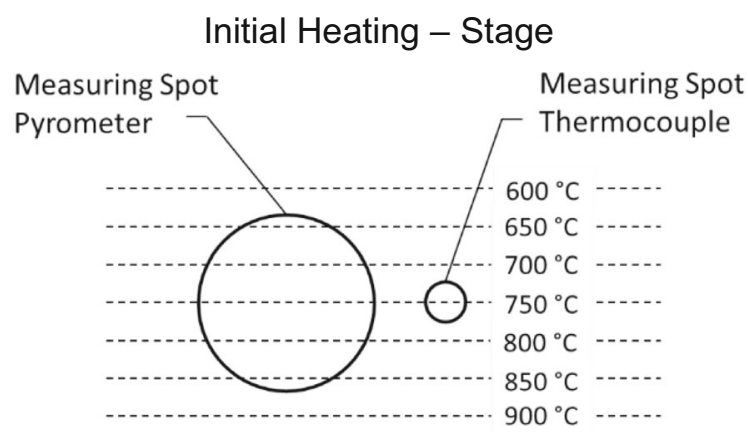

(a) steady-state temperature. The peak temperatures are dependent on the actual distance of the measuring spot from the beam centre, and these are nearly constant over the entire process duration (Fig. 8a). At the end of the process, the metal deposition stops, and the electron beam is switched off, resulting in a drop in temperature due to cooling.

As the initial position of the measuring spot of the pyrometer in relation to the centre of the beam can only be set manually, the nominal relative offset is subject to uncertainties. The relative positions need to be corrected, which is performed by means of applying the time derivative for the temperature curves (Fig. 8b). The actual relative position is determined by taking into account the period of time $\Delta t$ between the first peak at process initiation $(t$

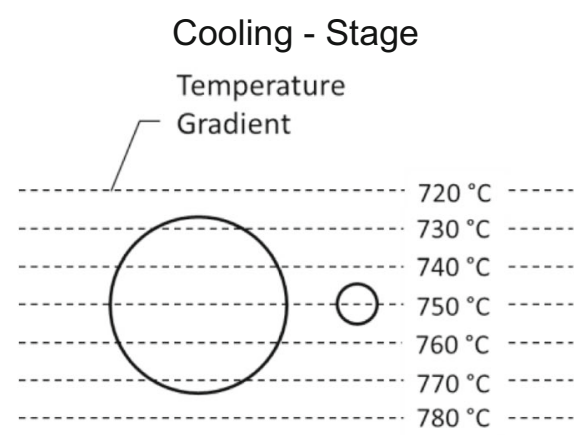

(b)

Fig. 6 Schematic illustration of the influence of the measured spot sizes in temperature fields with a steep temperature gradient (e.g. initial phase of heating) and $\mathbf{b}$ moderate temperature gradient (e.g. cooling phase) 


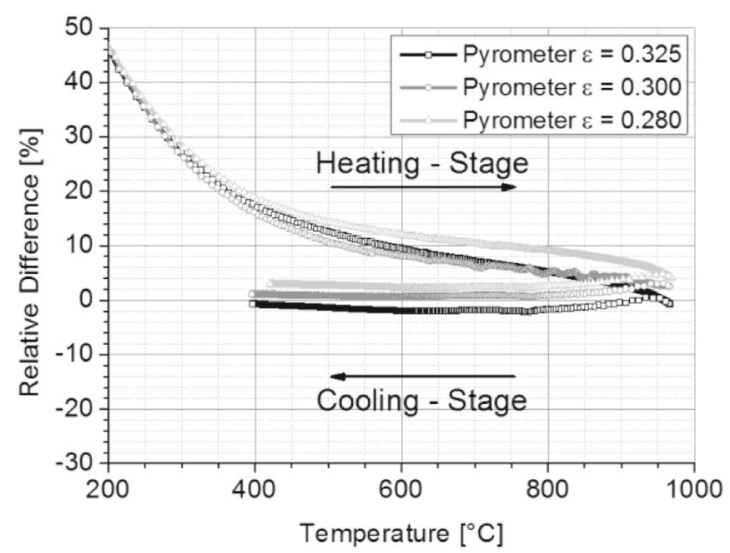

(a)

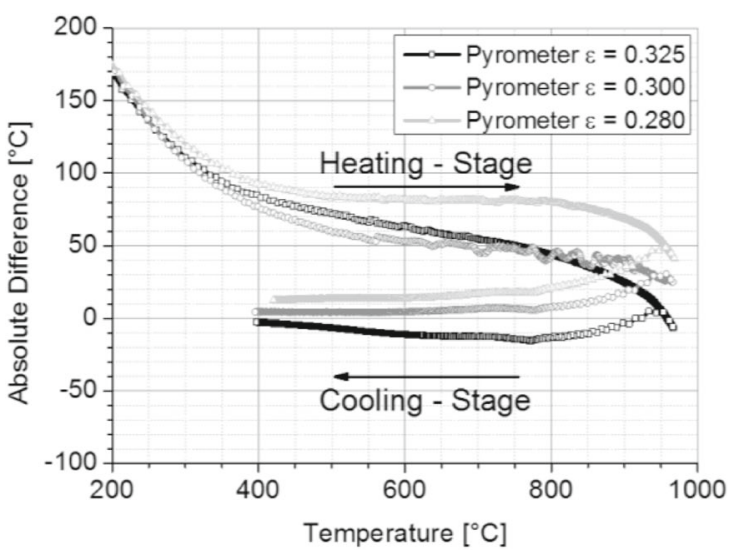

(b)

Fig. 7 Difference levels between contact and contactless temperature measurements for different emissivities, as described by a relative difference and $\mathbf{b}$ absolute difference depending on the temperature

$=0 \mathrm{~s}$ ) and the second peak at the transition from the substrate to the weld metal. Considering the predefined welding speed $\mathrm{v}_{\mathrm{w}}(9$ $\mathrm{mm} / \mathrm{s}$ ), the actual relative position can be derived and calculated as follows:

$x_{p o s}=v_{w} * \Delta t$

Based on the pyrometer measurements and the recorded quasi steady-state temperatures for corrected relative beam offset positions, the temperature profile was interpolated (Fig. 9a) and the associated cooling rates were derived (Fig. $9 b)$. In the temperature range of $1000-850{ }^{\circ} \mathrm{C}(\alpha+\beta$ field $)$, maximum and a minimum cooling rates of approx. 350 and $220^{\circ} \mathrm{C} / \mathrm{s}$ were determined. For the lower temperature level of $600{ }^{\circ} \mathrm{C}$, a cooling rate of about $80^{\circ} \mathrm{C} / \mathrm{s}$ was derived.

\subsubsection{Thermal cycles by thermal imaging}

In addition to the pyrometer measurements, the temperature profile was recorded with a near-infrared camera during the

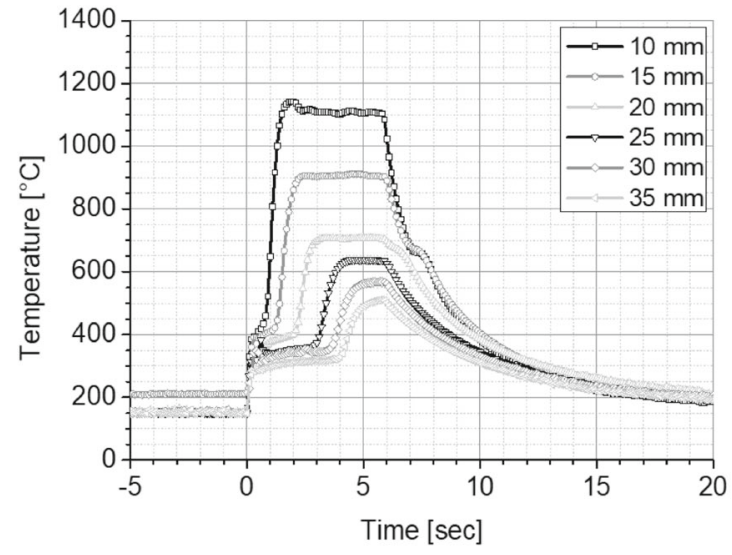

(a) single-track deposition. Since the thermal cycles were exported for different emissivities in the range of 0.1 to 1.0, numerous temperature profiles in the $y$ - (Fig. 10b), but also in the $x$-direction (Fig. 10c) are possible. As with the one-colour pyrometer, a suitable emissivity needs to be selected. To determine a suitable emission coefficient, the temperature profiles for the $x$ - and $y$-directions were evaluated with regard to the following geometric boundary conditions:

1 For the applied parameter configuration, the welding bead width is known and is approx. $5.6 \mathrm{~mm}$ [23]. Since the weld bead is symmetrical and the width is known, it can be assumed that the temperature recorded in the width of the weld bead should be equal to the solidus temperature at a certain emissivity $\left(T_{\text {solidus }} \approx\right.$ $\left.T_{(0, w / 2, \varepsilon)}\right)$ (Fig. 10b).

2 Tang et al. [27] simulated the transient fluid flow of the weld pool in EBF3, showing that the high temperature range is restricted to the area of direct electron beam exposure and has a steep temperature gradient to its surroundings. In the present study, the beam was continuously deflected to a

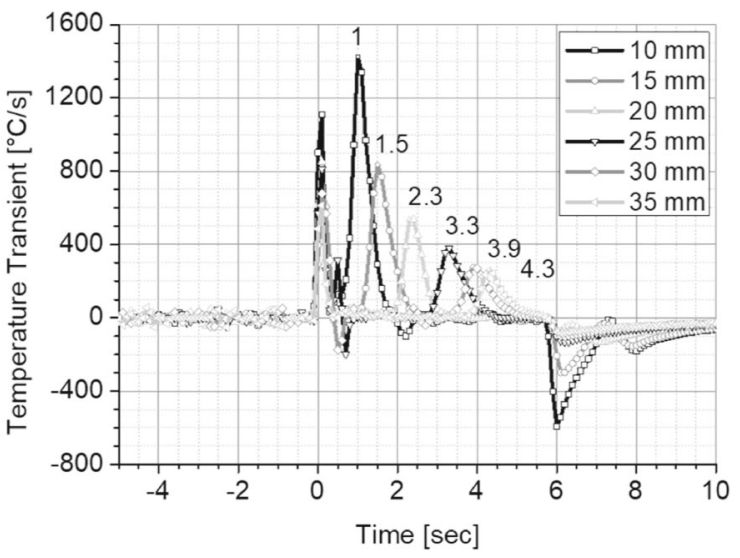

(b)

Fig. 8 a Contactless recorded thermal cycles for particular nominal positions relative to the beam centre. b Heating and cooling rates based on the derivation of measured temperature shown in a 


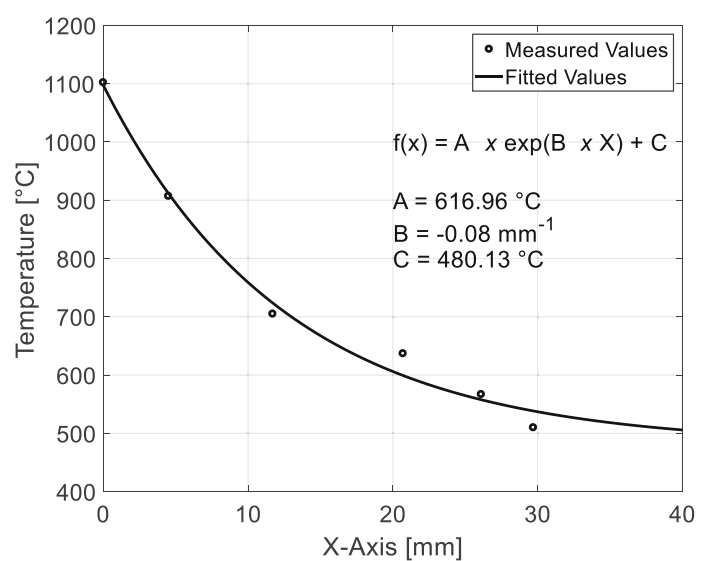

(a)

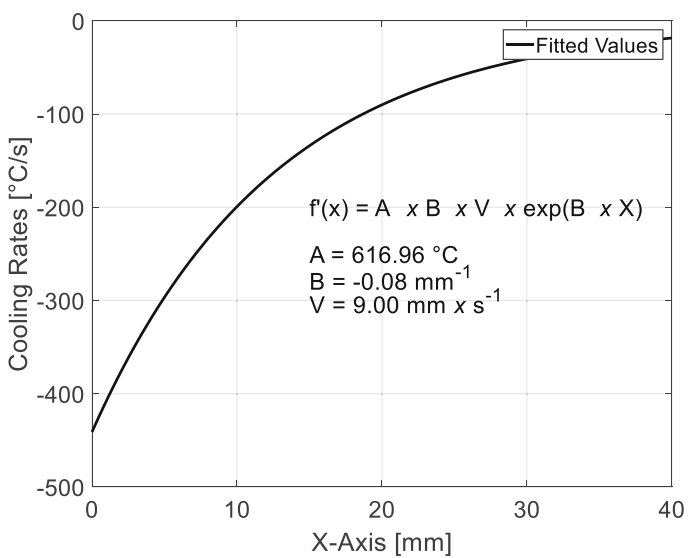

(b)

Fig. 9 a Contactless measured quasi steady-state temperatures depending on the actual relative position and derived exponential fit for temperature distribution. b Derived associated function of the cooling rate

circular area with a diameter of $4 \mathrm{~mm}$. Therefore, in the outer area of direct beam exposure, a temperature above the maximum recordable temperature of the thermal imaging camera $\left(T_{\text {limit }}=1800{ }^{\circ} \mathrm{C}\right)$ must be expected $\left(T_{\text {limit }}<T_{(0, \varnothing \text { Beam } /, \varepsilon)}\right)$ (Fig. 10b). Considering the limitations, only the temperature profile of the area with non-direct beam exposure can be captured.

3 Taking into account the temperature profile in the $x$-direction, a change in the temperature gradient during cooling can be noted (Fig. 10c). The near-infrared camera covers the temperature range from 1800 to $675{ }^{\circ} \mathrm{C}$, and the surface temperature is not only measured in the solid but also in the semi-solid and liquid states. The thermophysical properties (i.e. heat capacity, thermal conductivity, emissivity) vary with the temperature and physical state; heat flux/temperature profile changes noticeably at these transitions. The changes in the temperature gradients that occur during the cooling process can be assigned to the transitions from the liquid to the semi-solid and to the solid state, and the corresponding liquidus and solidus temperatures are known for Ti-6Al-4V (Fig. 10c).

Based on the temperature profiles in the $x$ - and $y$-directions and the presented boundary conditions, the near-infrared camera was calibrated with an emissivity $\varepsilon_{\mathrm{T}}$ of 0.3 . This value is close to the value used for the pyrometer, as the spectral ranges approach each other, and it correlates with values cited in the literature for titanium and titanium alloys [35, 47, 48] with similar spectral ranges measured under a vacuum.

Figure 11a shows the temperature profile as described by its isotherms in the quasi steady-state stage with a calibrated emissivity of 0.3 . The melt pool (liquid) and mushy zone (liquid + solid) length is approx. $6.5 \mathrm{~mm}$ and $2.1 \mathrm{~mm}$, respectively. Temperatures above the $\beta$-transus can be observed at a distance of up to $15 \mathrm{~mm}$ from the beam centre. The associated cooling profile was also derived (Fig. 11b), estimating rapid cooling rates (up to $1000^{\circ} \mathrm{C} / \mathrm{s}$ ) in the area just beyond the heat source.

Based on thermographic measurements, the temperature profile was interpolated (Fig. 12a) and the corresponding cooling rates were derived (Fig. 12b). In the temperature range of $850-1000{ }^{\circ} \mathrm{C}$, slower cooling rates of approx. $180-350{ }^{\circ} \mathrm{C} / \mathrm{s}$ were obtained.

\subsubsection{Comparison recorded thermal cycles by thermal imaging to pyrometry}

Figure 13 depicts the interpolated temperature curves as determined by using both contactless methods. While the thermal imaging camera covers the higher temperature levels, the pyrometer mainly covers temperature levels lower than $1100^{\circ} \mathrm{C}$. A superimposed temperature range for both methods is limited to the range of about $800-1100^{\circ} \mathrm{C}$. For temperatures below $875^{\circ} \mathrm{C}$, a significant deviation in the curves was observed; measurements made with the thermal imaging camera were higher than the surface temperature recorded by the pyrometer. This may be attributed to the fact that this temperature level recorded by pyrometer is already within the range of the lower temperature threshold that can be measured with the thermal imaging camera. The low intensity thermal radiation (reflections) reflected from the ambient zone inside the chamber may indicate a higher temperature level for the region of interest than is actually present. The presence of thermal reflections, especially when conducting experiments with metals, are a well-known drawback in thermal imaging, which needs to be taken into account when analysing the results. Other aspects also need to be considered, such as the selection of the respective constant emissivity for the respective devices. While the emissivity for the one-level pyrometer was selected based on a calibration for the temperature range 400 $1000{ }^{\circ} \mathrm{C}$, the emissivity for the NIR camera was calibrated based on temperatures from $1600{ }^{\circ} \mathrm{C}$ upwards. Since the overlapping temperature range is not in the primary calibration range of both 
Fig. 10 a Recorded temperature field with an emissivity coefficient of $\varepsilon=0.3$ and temperature profiles (taken along solid white lines) in $\mathbf{b} y$-direction $T=T(y, \varepsilon)$ and $\mathbf{c} x$-direction $T=$ $T(x, \varepsilon)$ for variable emissivity ranging from $\varepsilon=0.1-1.0$ for a single-track deposition in the 1 st layer

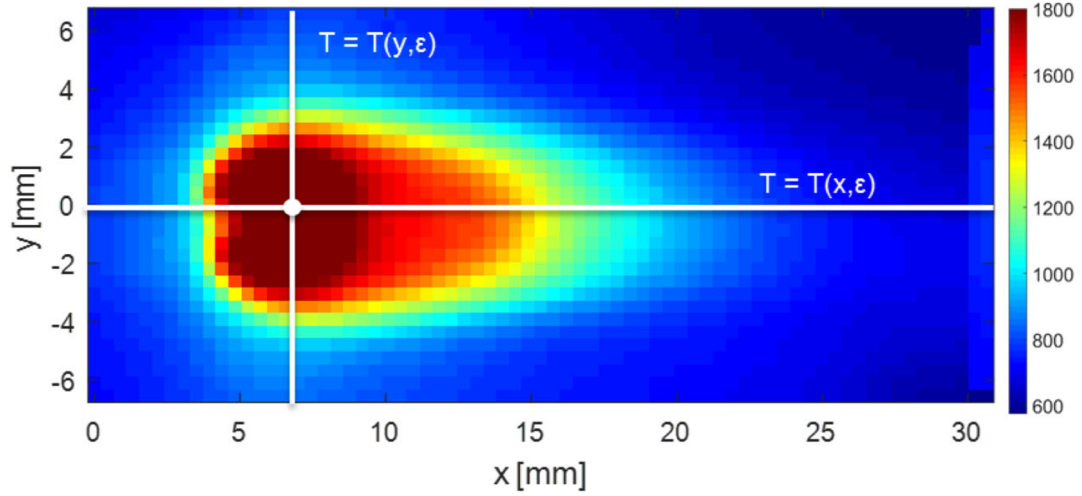

(a)

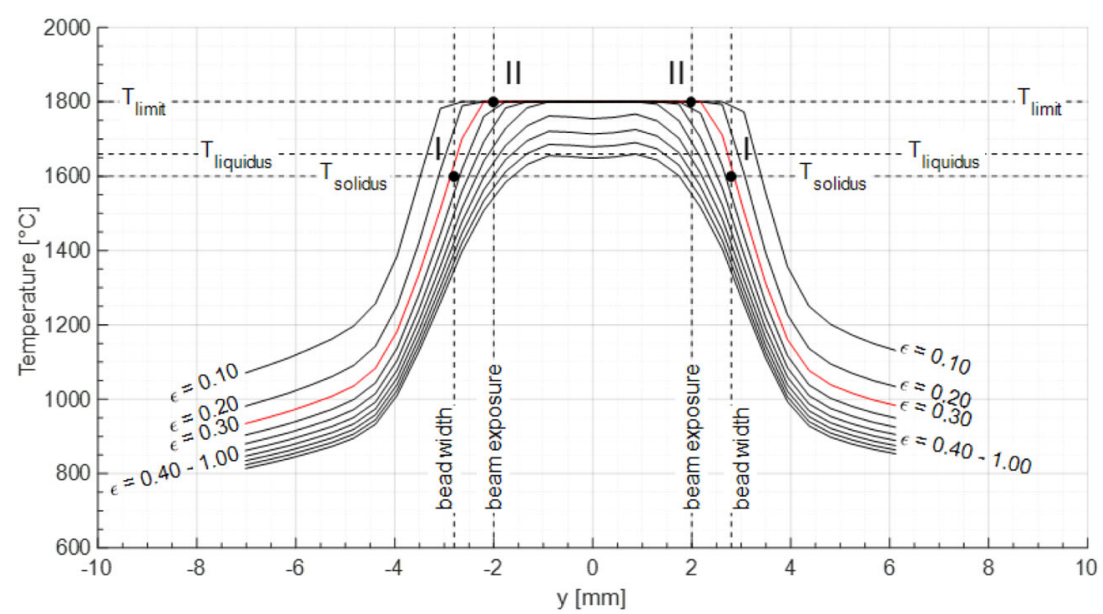

(b)

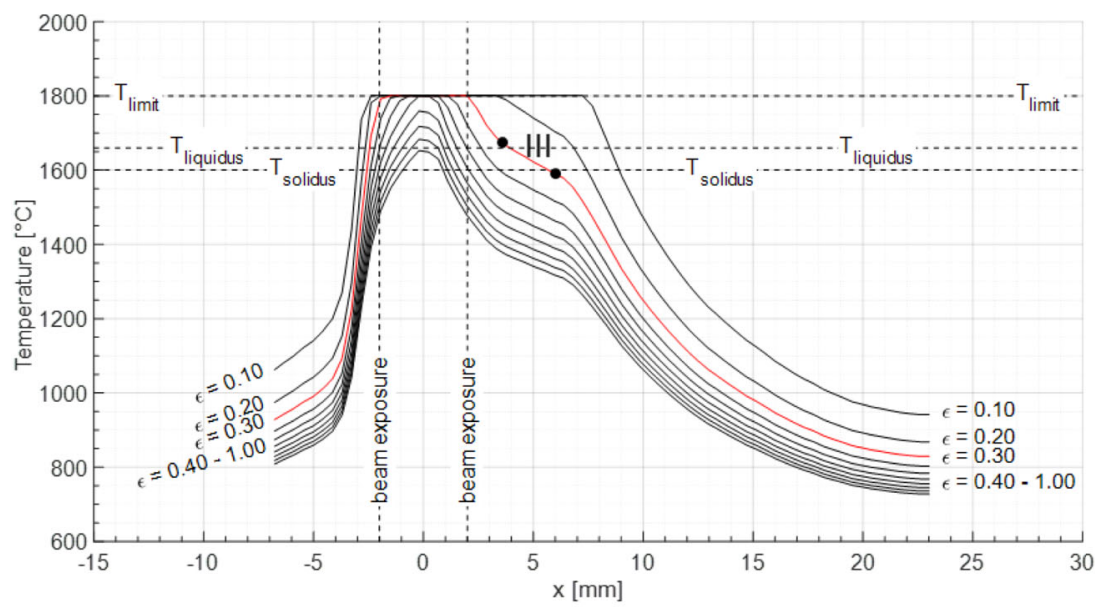

(c) techniques at once, a degree of uncertainty in the accuracy of this range can be assumed.

\subsection{Microstructural characterisation}

The microstructure of Ti-6Al-4V is sensitive to the thermal history, and cooling conditions play an essential role in the formation of the different morphological features of the $\alpha$ phase [49]. Transition products from the $\beta$ decomposition can arise and depend mainly on the thermal history of the deposited material. The evolving microstructure can consist of primary, secondary, plate-like, colony, grain boundary, acicular $\alpha$, Widmanstätten structures, or hexagonal $\alpha^{\prime}$ (martensite) $[11,50]$. 


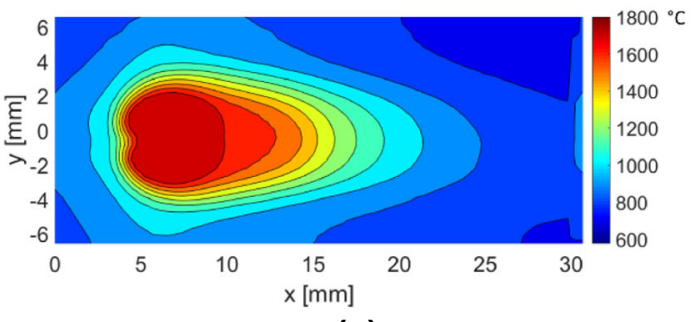

(a)

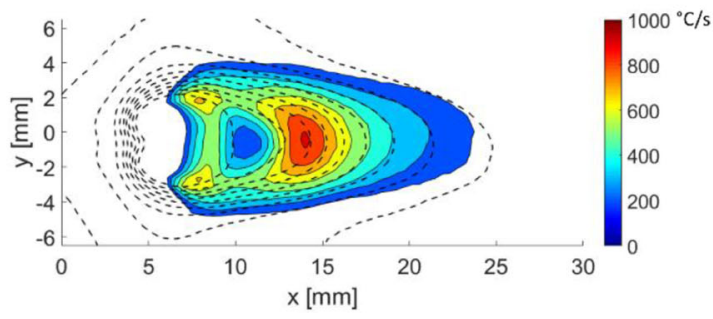

(b)

Fig. 11 a Temperature distribution in electron beam additive manufacturing as recorded using a near-infrared camera with an emissivity $\varepsilon_{T}$ of 0.3 . b The associated derived temperate transient distribution and isotherms (dashed lines) during Ti-6Al-4V metal deposition

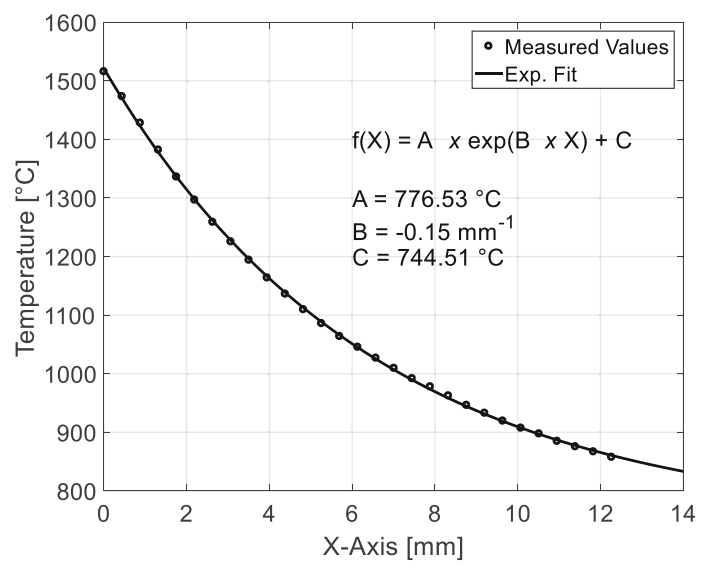

(a)

Fig. 12 a Quasi steady-state temperatures along the weld centreline measured by thermography, depending on the actual relative position of the measurement site, and the derived exponential fit for the temperature

Ahmed et al. [51] described the phase transformations that occurred during the cooling process in $\alpha+\beta$ alloy Ti-6Al-4V and summarised the results in a schematic diagram that depicted a continuous cooling event. While cooling rates of higher than $410{ }^{\circ} \mathrm{C} / \mathrm{s}$ lead to the formation of a fully martensitic $\alpha^{\prime}$ microstructure, lower cooling rates result in the formation of a mixed microstructure consisting of $\alpha^{\prime}$ and different morphological forms of diffusion-controlled $\alpha$ (Fig. 14) [51].

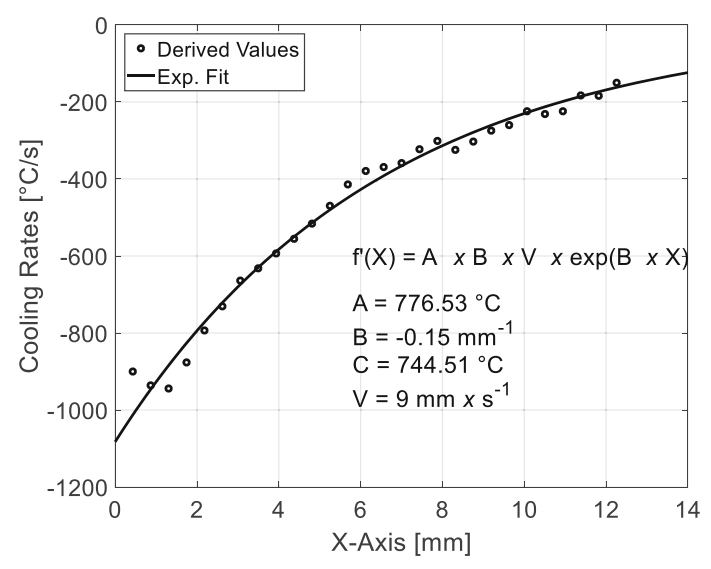

(b)

distribution. b Derived associated function of the temperature transient to describe the cooling rates

The microstructure of the single-track deposition transverse to the welding direction was investigated using a BSE detector and EBSD, which is shown in Figs. 15 and 16, respectively. The different orientations of the lamellas of $\alpha / \alpha^{\prime}$ are shown in the IPF map in Fig. 16a. Their maximum thickness is $\sim 1 \mu \mathrm{m}$. Zones of very fine and undistinguishable $\alpha / \alpha^{\prime}$ are shown between the thicker $\alpha$ phases, as highlighted by the yellow dashed circles in Fig. 15.
Fig. 13 a Derived quasi-steadystate temperature distribution by pyrometry and thermal imaging for single-track Ti-6Al-4V deposition. b Detail A of a, showing the superimposed temperature range

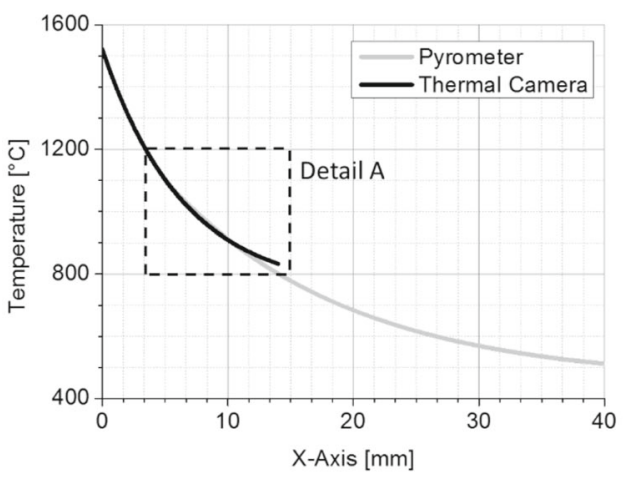

(a)

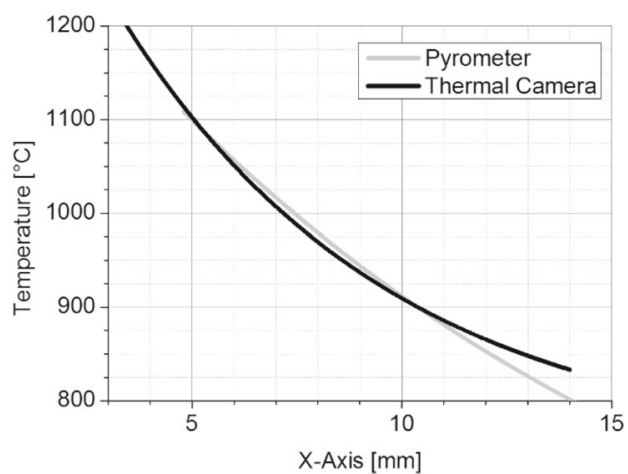

(b) 
Fig. 14 Schematic illustration of a continuous cooling transformation (CCT) diagram for Ti-6Al-4V (based on [51]); dashed area represents expected cooling rates in $\mathrm{EBF}^{3}$ determined in this work

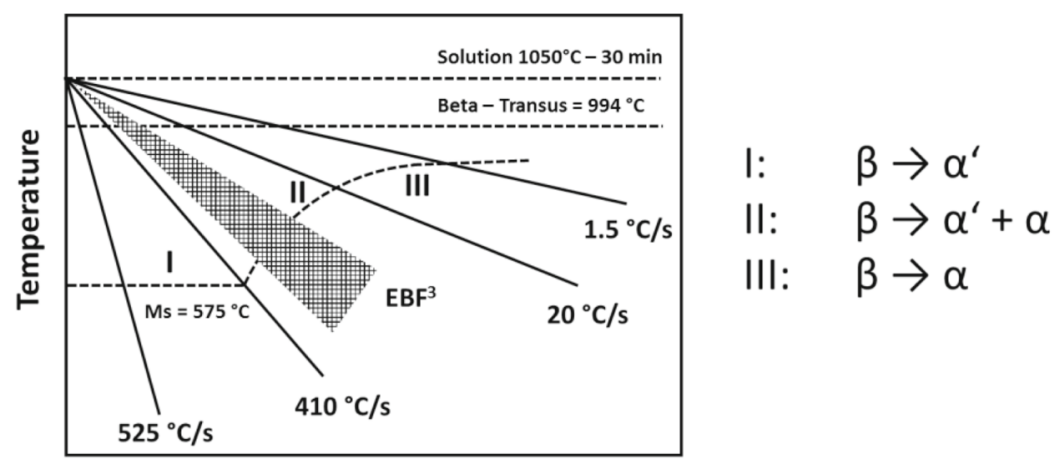

Time
The different sizes of the platelets of $\alpha$ or acicular shape of $\alpha$ ' are shown in Fig. 16b. The local misorientation distribution is illustrated by the kernel average misorientation (KAM) map in Fig. 16c. Finally, Fig. 16d shows the distribution of the confidence index for the investigated area. The very fine particles shown in Fig. 16c also exhibit a confidence index (CI) in Fig. 16d, indicating that they are $\alpha$ '. The thicker particles with higher image quality (IQ) values and low KAM are considered to be fine platelets of fine $\alpha$-phase. If the regions in blue and green in Fig. 16d are considered as representative of $\alpha$, the fraction of $\alpha^{\prime}$ can be estimated to be $\sim 40 \%$, while the remaining $60 \%$ would correspond to acicular $\alpha$-phase. The complex thermocycle with a rapid cooling period leads to complex residual stress distribution. This, in turn, causes local plastic deformation and leads to the formation of a local misorientation spread and substructures within the $\alpha / \alpha$ '. The massive formation of $\alpha^{\prime}$ and the temperature gradient within the single track that occurs during the rapid cooling phase serve as the sources of the residual stresses. The regions indicated by the black arrow in Fig. 16c are regions where local plastic deformation occurred during the formation of the microstructure in the deposition phase. The measurements refer only to the first single track. Subsequent layers further reduce the stresses, as observed in [23].

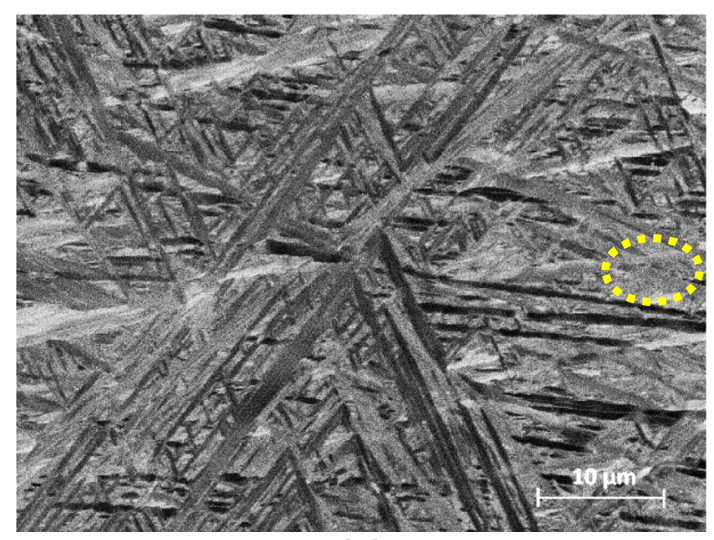

(a)

\section{Summary and conclusion}

In the present work, it was possible to demonstrate the feasibility of applying contactless infrared irradiation temperature measurement in electron beam additive manufacturing. Two different techniques, pyrometry and thermal imaging, were used to collect spatial and temporal information while metal was deposited on a substrate under vacuum. The near-infrared camera could be used to cover the higher temperature range (i.e. the transition from liquidus to semi-solid and on to solid), while the one-colour pyrometer could mainly be used to record lower temperatures (i.e. at which diffusion and structural changes take place). Based on the recorded and derived temperature profiles, predictions for the evolved microstructure were made and were compared with the characterised weld metal deposit. The results can be summarised as follows:

\subsection{Pyrometry}

- The evaporation loss of aluminium that occurred when Ti$6 \mathrm{Al}-4 \mathrm{~V}$ is processed interferes with the contactless temperature measurements made in the vacuum chamber. Placing a continuous foil transport in front of the pyrom-

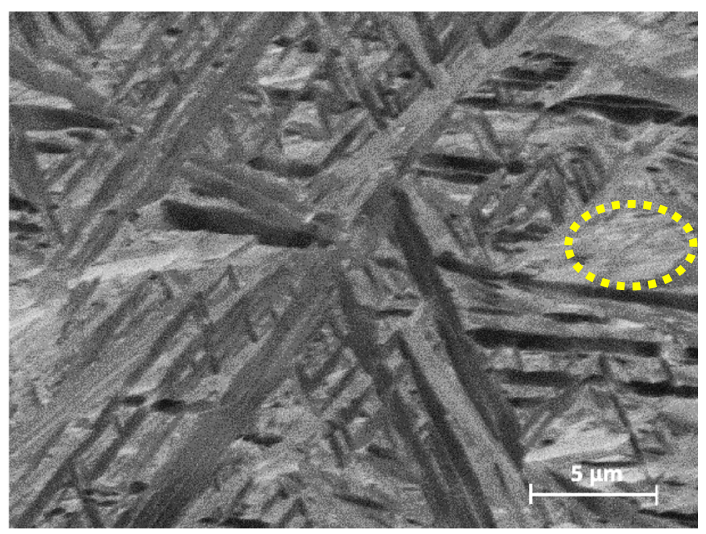

(b)

Fig. 15 Backscattered electron micrographs of the single-track deposited Ti-6Al-4V transverse to the welding direction 
Fig. 16 Electron backscatter diffraction results in the cross section of the single track. a Inverse pole figure (IPF) map. b Image quality (IQ) map. c Kernel average misorientation (KAM) map. d Confidence index (CI) map

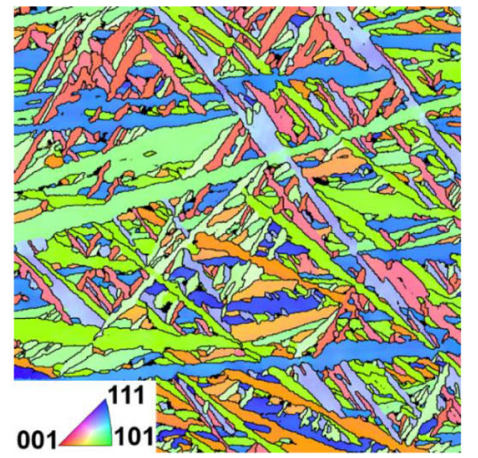

(a)

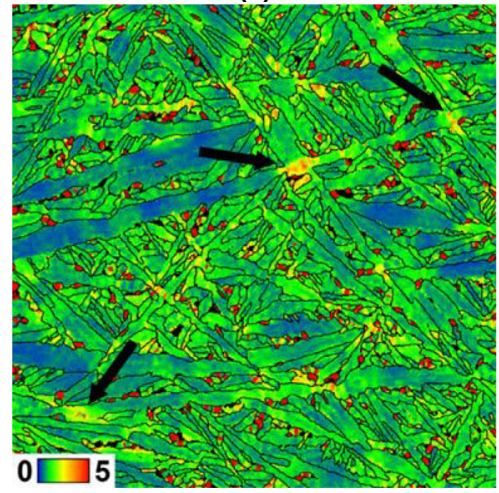

(c)

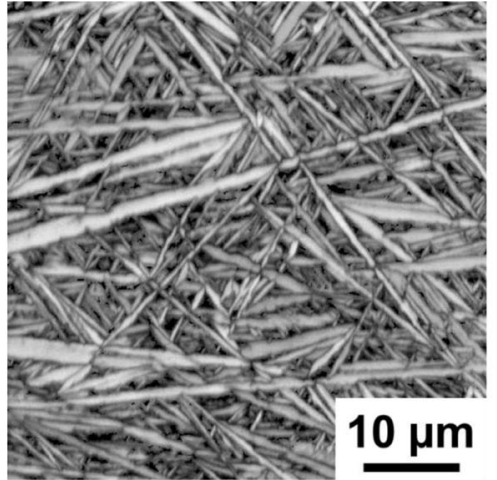

(b)

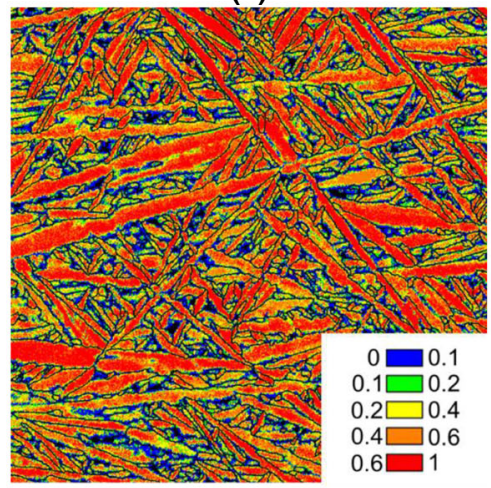

(d) eter lens ensures a constant optical path (transmittance) and enables reliable and continuous temperature measurements.

- A benchmark test, including heating and cooling stages, was designed to calibrate the pyrometer with thermocouples and compare the recorded thermal cycles. In the initial stage of heating, the associated steep temperature gradient results in comparatively high degrees of relative difference and deviation due to the different spatial resolution of the spot-welded thermocouples and pyrometer. At later stages of heating and in the cooling stage, the lower and more moderate temperature gradient results in more accurate results and higher consistency among the compared temperature curves.

- Regarding the spectral range covered by the single-colour pyrometer and the surface condition of the material tested, a calibrated emissivity of 0.325 results in a minimal relative difference for the temperature region of interest and in the cooling stage. The corresponding emissivity for the one-colour pyrometer was chosen for the subsequent experiment and metal deposition.

- Single-track metal deposition of Ti-6Al-4V was performed, and temperature cycles were recorded for several positions relative to the beam centre. To determine the spatial temperature distribution, the quasi-stationary peak temperatures were evaluated as a function of the offset from the beam centre and mathematically described by exponential fitting in order to examine the temperature gradient and derive the corresponding temperature transient function.

- Based on the measurements and interpolations, cooling rates of approx. $220-350{ }^{\circ} \mathrm{C} / \mathrm{s}$ could be determined by contactless pyrometry in the temperature range of 850 $1000{ }^{\circ} \mathrm{C}(\alpha+\beta$ field $)$. At lower temperatures, e.g. 600 ${ }^{\circ} \mathrm{C}$, a cooling rate of about $80^{\circ} \mathrm{C} / \mathrm{s}$ is still possible.

\subsection{Thermal imaging}

- Temperature profiles for emissivities between 0.1 and 1.0 for the quasi steady-stage stage during weld metal deposition were exported. Geometric boundary conditions and change in temperature gradient were used to calibrate an emissivity of 0.3 .

- The temperature profile for an emissivity of 0.3 was exported, and the associated temperature transient profile was derived. In addition, a phase transformation starts to take place in the rear area and $15 \mathrm{~mm}$ away from the beam centre. Locally, high cooling rates (up to $1000^{\circ} \mathrm{C} / \mathrm{s}$ ) were measured in the vicinity of the direct beam exposure, and a decrease was observed towards the rear as the distance from the electron beam and metal deposition increased.

- Based on the measurements and interpolation, it was possible to record cooling rates of approx. $180-350^{\circ} \mathrm{C} / \mathrm{s}$ by 
contactless thermal imaging in the temperature range of $850-1000{ }^{\circ} \mathrm{C}(\alpha+\beta$ field $)$.

\subsection{Microstructure characterisation}

- A microstructure consisted of fine acicular $\alpha$ phase and $\alpha$, was observed after a single-track deposition.

- The residual stress distribution in the very first single track, which caused local plastic deformation and resulted in the formation of local misorientation during the cooling phase, can be characterised by EBSD measurement.

Acknowledgements The authors thank pro-beam GmbH \& Co. KGaA and voestalpine Böhler Aerospace $\mathrm{GmbH} \& \mathrm{Co} \mathrm{KG}$ for the provision of the near-infrared thermal camera and substrate and filler wire for the experiments.

Funding Open access funding provided by Graz University of Technology. The authors carried out this work as part of the following projects: "Dobeneck-Technologie-Stiftung", COMET programme within the COMET K2 Center "Integrated Computational Material, Process and Product Engineering (IC-MPPE)" (Project No 859480), and CD Laboratory for Design of High-Performance Alloys by Thermomechanical Processing, supported by the Christian Doppler Society (Project F37729). The COMET programme is supported by the Austrian Federal Ministries for Transport, Innovation and Technology (BMVIT) and for Digital Economic Affairs (BMDW), represented by the Austrian Research Promotion Agency (FFG), and the Austrian federal states of Styria, Upper Austria, and Tyrol. Open Access Funding by the Graz University of Technology.

\section{Declarations}

Conflict of interest The authors declare that they have no conflict of interest.

Open Access This article is licensed under a Creative Commons Attribution 4.0 International License, which permits use, sharing, adaptation, distribution and reproduction in any medium or format, as long as you give appropriate credit to the original author(s) and the source, provide a link to the Creative Commons licence, and indicate if changes were made. The images or other third party material in this article are included in the article's Creative Commons licence, unless indicated otherwise in a credit line to the material. If material is not included in the article's Creative Commons licence and your intended use is not permitted by statutory regulation or exceeds the permitted use, you will need to obtain permission directly from the copyright holder. To view a copy of this licence, visit http://creativecommons.org/licenses/by/4.0/.

\section{References}

1. ISO 17296-2:2015 Additive manufacturing — general principles - part 2: overview of process categories and feedstock

2. Plangger J, Schabhüttl P, Vuherer T, Enzinger N (2019) CMT additive manufacturing of a high strength steel alloy for application in crane construction. Metals (Basel) 9:1-14. https://doi.org/10. 3390/met9060650

3. Bourlet C, Zimmer-Chevret S, Pesci R, Bigot R, Robineau A, Scandella F (2020) Microstructure and mechanical properties of high strength steel deposits obtained by wire-arc additive manufacturing. J Mater Process Technol 285:116759. https://doi. org/10.1016/j.jmatprotec.2020.116759

4. Wang C, Liu TG, Zhu P, Lu YH, Shoji T (2020) Study on microstructure and tensile properties of 316L stainless steel fabricated by CMT wire and arc additive manufacturing. Mater Sci Eng A 796: 140006. https://doi.org/10.1016/j.msea.2020.140006

5. Klein T, Schnall M (2020) Control of macro-/microstructure and mechanical properties of a wire-arc additive manufactured aluminum alloy. Int J Adv Manuf Technol 108:235-244. https://doi.org/ 10.1007/s00170-020-05396-6

6. Morais PJ, Gomes B, Santos P, Gomes M, Gradinger R, Schnall M, Bozorgi S, Klein T, Fleischhacker D, Warczok P, Falahati A, Kozeschnik E (2020) Characterisation of a high-performance Al$\mathrm{Zn}-\mathrm{Mg}-\mathrm{Cu}$ alloy designed for wire arc additive manufacturing. Materials (Basel) 13:1610. https://doi.org/10.3390/ma13071610

7. Aboulkhair NT, Simonelli M, Parry L, Ashcroft I, Tuck C, Hague R (2019) 3D printing of aluminium alloys: additive manufacturing of aluminium alloys using selective laser melting. Prog Mater Sci 106: 100578. https://doi.org/10.1016/j.pmatsci.2019.100578

8. Dhinakaran V, Ajith J, Fathima Yasin Fahmidha A, Jagadeesha T, Sathish T, Stalin B (2020) Wire arc additive manufacturing (WAAM) process of nickel based superalloys-a review. Mater Today Proc 21:920-925. https://doi.org/10.1016/j.matpr.2019.08. 159

9. Babu SS, Raghavan N, Raplee J, Foster SJ, Frederick C, Haines M, Dinwiddie R, Kirka MK, Plotkowski A, Lee Y, Dehoff RR (2018) Additive manufacturing of nickel superalloys: opportunities for innovation and challenges related to qualification. Metall Mater Trans A Phys Metall Mater Sci 49:3764-3780. https://doi.org/10.1007/ s11661-018-4702-4

10. Kong D, Dong C, Ni X, Zhang L, Man C, Yao J, Ji Y, Ying Y, Xiao K, Cheng X, Li X (2019) High-throughput fabrication of nickelbased alloys with different $\mathrm{Nb}$ contents via a dual-feed additive manufacturing system: Effect of $\mathrm{Nb}$ content on microstructural and mechanical properties. J Alloys Compd 785:826-837. https:// doi.org/10.1016/j.jallcom.2019.01.263

11. Leyens C, Peters M (2003) Offshore applications for titanium alloys. Titan Titan Alloy Fundam Appl. https://doi.org/10.1002/ 3527602119

12. Allen J (2006) An Investigation into the Comparative Costs of Additive Manufacture vs. Machine from Solid for Aero Engine Parts. Cost Eff Manuf via Net-Shape Process 17-1-17-10

13. Vázquez L, Rodríguez N, Rodríguez I, Alberdi E, Álvarez P (2020) Influence of interpass cooling conditions on microstructure and tensile properties of Ti-6Al-4V parts manufactured by WAAM. Weld World 64:1377-1388. https://doi.org/10.1007/s40194-02000921-3

14. McAndrew AR, Alvarez Rosales M, Colegrove PA, Hönnige JR, Ho A, Fayolle R, Eyitayo K, Stan I, Sukrongpang P, Crochemore A, Pinter Z (2018) Interpass rolling of Ti-6Al-4V wire + arc additively manufactured features for microstructural refinement. Addit Manuf 21:340-349. https://doi.org/10.1016/j.addma.2018.03.006

15. Caballero A, Ding J, Bandari Y, Williams S (2019) Oxidation of Ti6Al-4V during wire and arc additive manufacture. 3D Print Addit Manuf 6:91-98. https://doi.org/10.1089/3dp.2017.0144

16. Ouchi C, Iizumi H, Mitao S (1998) Effects of ultra-high purification and addition of interstitial elements on properties of pure titanium and titanium alloy. Mater Sci Eng A 243:186-195. https://doi.org/ 10.1016/s0921-5093(97)00799-5

17. Yan M, Dargusch MS, Ebel T, Qian M (2014) A transmission electron microscopy and three-dimensional atom probe study of 
the oxygen-induced fine microstructural features in as-sintered Ti6Al-4V and their impacts on ductility. Acta Mater 68:196-206. https://doi.org/10.1016/j.actamat.2014.01.015

18. Park HK, Na TW, Yang SM, Kim GH, Lee BS, Kim HG (2019) Thermodynamic analysis of oxygen refining during electron-beam additive manufacturing of pure titanium products. Mater Lett 236: 106-108. https://doi.org/10.1016/j.matlet.2018.10.083

19. Taminger K, Hafley R (2003) Electron beam freeform fabrication: a rapid metal deposition process. Proc 3rd Annu Automot Compos Conf 9-10

20. Wanjara P, Watanabe K, De Formanoir C, Yang Q, Bescond C, Godet S, Brochu M, Nezaki K, Gholipour J, Patnaik P (2019) Titanium Alloy Repair with Wire-Feed Electron Beam Additive Manufacturing Technology. Adv Mater Sci Eng 2019:1-23. https://doi.org/10.1155/2019/3979471

21. Xu J, Zhu J, Fan J, Zhou Q, Peng Y, Guo S (2019) Microstructure and mechanical properties of Ti-6Al-4V alloy fabricated using electron beam freeform fabrication. Vacuum 167:364-373. https:// doi.org/10.1016/j.vacuum.2019.06.030

22. Savchenko NL (2019) Modification of the column structure of wire-feed electron-beam additive manufactured Ti-6Al-4V alloy. AIP Conf Proc 2167:6-11. https://doi.org/10.1063/1.5132176

23. Pixner F, Warchomicka F, Peter P, Steuwer A, Colliander MH, Pederson R, Enzinger N (2020) Wire-based additive manufacturing of Ti-6Al-4V using electron beam technique. Materials (Basel) 13: 3310. https://doi.org/10.3390/ma13153310

24. Guimarães R, Pixner F, Trimmel G, Hobisch J, Rath T, Fernandez F, Enzinger N, Amancio-Filho ST (2020) The electron beam freeform fabrication of NiTi shape memory alloys. Part I: Microstructure and physical-chemical behavior. Proc Inst Mech Eng L J Mater Des Appl 146442072097505. https://doi.org/10. $1177 / 1464420720975059$

25. Gockel J, Beuth J, Taminger K (2014) Integrated control of solidification microstructure and melt pool dimensions in electron beam wire feed additive manufacturing of Ti-6Al-4V. Addit Manuf 1-4: 119-126. https://doi.org/10.1016/j.addma.2014.09.004

26. Gockel J, Fox J, Beuth J, Hafley R (2015) Integrated melt pool and microstructure control for Ti-6Al-4V thin wall additive manufacturing. Mater Sci Technol (United Kingdom) 31:912-916. https://doi. org/10.1179/1743284714Y.0000000704

27. Tang Q, Pang S, Chen B, Suo H, Zhou J (2014) A three dimensional transient model for heat transfer and fluid flow of weld pool during electron beam freeform fabrication of Ti-6-Al-4-V alloy. Int J Heat Mass Transf 78:203-215. https://doi.org/10.1016/j. ijheatmasstransfer.2014.06.048

28. Lütjering G, Williams JC (2007) Titanium. https://doi.org/10.1007/ 978-3-540-73036-1

29. Ding XP, Li HM, Zhu JQ, Wang GY, Cao HZ, Zhang Q, Ma HL (2017) Application of infrared thermography for laser metal-wire additive manufacturing in vacuum. Infrared Phys Technol 81:166169. https://doi.org/10.1016/j.infrared.2016.12.017

30. Zalameda JN, Burke ER, Hafley RA, Taminger KM, Domack CS, Brewer A, Martin RE (2013) Thermal imaging for assessment of electron-beam freeform fabrication (EBF 3 ) additive manufacturing deposits. Thermosense Therm Infrared Appl XXXV 8705: 87050M. https://doi.org/10.1117/12.2018233

31. Li D, Liu R, Zhao X (2019) Overview of in-situ temperature measurement for metallic additive manufacturing: how and then what. Solid Free Fabr 2019 Proc 30th Annu Int 1596-1610

32. Hagqvist P, Sikström F, Christiansson AK (2013) Emissivity estimation for high temperature radiation pyrometry on Ti-6Al-4V.
Meas J Int Meas Confed 46:871-880. https://doi.org/10.1016/j. measurement.2012.10.019

33. Scotti A (2019) The potential of IR pyrometry for monitoring interpass temperature in wire + arc additive manufacturing. Evol Mech Eng. https://doi.org/10.31031/eme.2019.03.000553

34. Del Campo L, Pérez-Sáez RB, Tello MJ, Esquisabel X, Fernández I (2006) Armco iron normal spectral emissivity measurements. Int J Thermophys 27:1160-1172. https://doi.org/10.1007/s10765-0060081-y

35. González-Fernández L, Risueño E, Pérez-Sáez RB, Tello MJ (2012) Infrared normal spectral emissivity of Ti-6Al-4V alloy in the 500-1150 K temperature range. J Alloys Compd 541:144-149. https://doi.org/10.1016/j.jallcom.2012.06.117

36. Rodrigues TA, Duarte V, Avila JA, Santos TG, Miranda RM, Oliveira JP (2019) Wire and arc additive manufacturing of HSLA steel: Effect of thermal cycles on microstructure and mechanical properties. Addit Manuf 27:440-450. https://doi.org/10.1016/j. addma.2019.03.029

37. Lee SH (2020) CMT-based wire arc additive manufacturing using 3161 stainless steel: effect of heat accumulation on the multi-layer deposits. Metals (Basel) 10. https://doi.org/10.3390/met10020278

38. Wu B, Ding D, Pan Z, Cuiuri D, Li H, Han J, Fei Z (2017) Effects of heat accumulation on the arc characteristics and metal transfer behavior in wire arc additive manufacturing of Ti6Al4V. J Mater Process Technol 250:304-312. https://doi.org/10.1016/j. jmatprotec.2017.07.037

39. Wu B, Pan Z, Ding D, Cuiuri D, Li H (2018) Effects of heat accumulation on microstructure and mechanical properties of Ti6Al4V alloy deposited by wire arc additive manufacturing. Addit Manuf 23:151-160. https://doi.org/10.1016/j.addma.2018.08.004

40. Chen T, Pang S, Tang Q, Suo H, Gong S (2016) Evaporation ripped metallurgical pore in electron beam freeform fabrication of Ti-6-Al4-V. Mater Manuf Process 31:1995-2000. https://doi.org/10.1080/ 10426914.2015.1127948

41. Juechter V, Scharowsky T, Singer RF, Körner C (2014) Processing window and evaporation phenomena for Ti-6Al-4V produced by selective electron beam melting. Acta Mater 76:252-258. https:// doi.org/10.1016/j.actamat.2014.05.037

42. Semiatin SL, Ivanchenko VG, Akhonin SV, Ivasishin OM (2004) Diffusion models for evaporation losses during electron-beam melting of alpha/beta-titanium alloys. Metall Mater Trans B Process Metall Mater Process Sci 35:235-245. https://doi.org/10.1007/ s11663-004-0025-5

43. Michelato P, Monaco L, Sertore D, Pagani C, Battista V, Corniani G, Festa M (2013) In-vacuum temperature measurement of nioboium components using infrared pyrometry during electron beam welding procedure. IPAC 2013 Proc 4th Int Part Accel Conf 2334-2336

44. Fuchs J, Schneider C, Enzinger N (2018) Wire-based additive manufacturing using an electron beam as heat source. Weld World 62:267-275. https://doi.org/10.1007/s40194-017-0537-7

45. Chiumenti M, Cervera M, Dialami N, Wu B, Jinwei L, Agelet de Saracibar C (2016) Numerical modeling of the electron beam welding and its experimental validation. Finite Elem Anal Des 121:118-133. https://doi.org/10.1016/j.finel.2016.07.003

46. Brandon DG (1966) The structure of high-angle grain boundaries. Acta Metall 14:1479-1484. https://doi.org/10.1016/0001-6160(66) 90168-4

47. Bradshaw FJ (1950) The optical emissivity of titanium and zirconium. Proc Phys Soc Sect B 63:573-577. https://doi.org/10.1088/ 0370-1301/63/8/304 
48. Michels WC, Wilford S (1949) The physical properties of titanium. I. Emissivity and resistivity of the commercial metal. J Appl Phys 20:1223-1226. https://doi.org/10.1063/1.1698312

49. Buzolin RH, Weiß D, Krumphals A, Lasnik M, Poletti MC (2020) Modelling the competitive growth of primary, allotriomorphic, and secondary alpha in Ti-6Al-4V. Metall Mater Trans A 51:39673980. https://doi.org/10.1007/s11661-020-05810-4

50. Brandl E, Schoberth A, Leyens C (2012) Morphology, microstructure, and hardness of titanium (Ti-6Al-4V) blocks deposited by wire-feed additive layer manufacturing (ALM). Mater Sci Eng A 532:295-307. https://doi.org/10.1016/j.msea.2011.10.095

51. Ahmed T, Rack HJ (1998) Phase transformations during cooling in $\alpha+\beta$ titanium alloys. Mater Sci Eng A 243:206-211. https://doi. org/10.1016/s0921-5093(97)00802-2

Publisher's note Springer Nature remains neutral with regard to jurisdictional claims in published maps and institutional affiliations. 